Börner, Katy, Fileve Palmer, Julie M. Davis, Elisha F. Hardy, Stephen M. Uzzo, Bryan J. Hook. 2009.

Teaching Children the Structure of Science. Proceedings of the Visualization and Data Analysis Conference San Jose, CA, 1/19/09-1/20/09.

\title{
Teaching Children the Structure of Science
}

\author{
Katy Börner, Fileve Palmer, Julie M. Davis, Elisha Hardy \\ katy | ftpalmer | efhardy@indiana.edu, jsmarie@gmail.com \\ Indiana University, Bloomington, IN 47405, USA \\ Stephen M. Uzzo \\ New York Hall of Science \\ Flushing Meadows Corona Park, NY 11368, USA \\ suzzo@nyscience.org \\ Bryan J. Hook \\ 3400 S. Tulip Avenue, Bloomington, IN 47403, USA \\ bryhook@gmail.com
}

Cyberinfrastructure for Network Science Center, School of Library and Information Science

\begin{abstract}
Maps of the world are common in classroom settings. They are used to teach the juxtaposition of natural and political functions, mineral resources, political, cultural and geographical boundaries; occurrences of processes such as tectonic drift; spreading of epidemics; and weather forecasts, among others. Recent work in scientometrics aims to create a map of science encompassing our collective scholarly knowledge. Maps of science can be used to see disciplinary boundaries; the origin of ideas, expertise, techniques, or tools; the birth, evolution, merging, splitting, and death of scientific disciplines; the spreading of ideas and technology; emerging research frontiers and bursts of activity; etc. Just like the first maps of our planet, the first maps of science are neither perfect nor correct. Today's science maps are predominantly generated based on English scholarly data: Techniques and procedures to achieve local and global accuracy of these maps are still being refined, and a visual language to communicate something as abstract and complex as science is still being developed. Yet, the maps are successfully used by institutions or individuals who can afford them to guide science policy decision making, economic decision making, or as visual interfaces to digital libraries. This paper presents the process and results of creating hands-on science maps for kids that teaches children ages 4-14 about the structure of scientific disciplines. The maps were tested in both formal and informal science education environments. The results show that children can easily transfer their (world) map and concept map reading skills to utilize maps of science in interesting ways.
\end{abstract}

Keywords: science, maps, children, education, cross-modal, haptic learning, visual learning

\section{Introduction}

The prevailing process for learning science, math and technology continues to embrace specialization and teaching topics and disciplines as separate entities. Mathematics, physics, biology, and many other subjects are taught in isolation by different teachers. However, science - particularly today - is highly interdisciplinary and interconnected. Almost all of humanity's major challenges require a close collaboration of scientists from different disciplines. The lonely genius, filled with vision and driven to exhaustion by his or her dream has little chance to succeed. Breakthrough research or inventions cannot be produced ex nihilo. Cutting edge science involves very large datasets, advanced computational infrastructures and visualization techniques, and a close collaboration with computer scientists and engineers.

How can children start to understand the complex interplay of the different sciences? How can they get an intuitive understanding of the importance of math and how much it is needed to succeed in many if not all of the other sciences? What does it mean for teaching, learning, and job opportunities if the biomedical sciences account for $50 \%$ of all sciences? Can we make them see the central position of computer science and its evolving symbiosis with all other aptly named 'computational X' sciences? Can we offer them a means to see the emergence and evolution of new sciences, e.g., nano* or neuro*? How can we empower them to search for a certain expertise in the correct scientific discipline? How can we teach them to appreciate the very diverse cultures, research approaches, and languages that exist in the different sciences and enable them to 'speak' more than one science in order to collaborate across scientific boundaries? Last but not least, how can we engage children in the work of real scientists, have them share the excitement of discovery, and allow them to find their own 'place' in science?

Today, children commonly use Google if they need an answer. They ask their siblings to type in words if they cannot yet spell them correctly and have the results read to them. In fact, almost all of us regularly use search

(C)2009 Society of Photo-Optical Instrumentation Engineers.

This paper was published in Proceedings of SPIE-IS\&T Electronic Imagine, Vol. 7243. SPIE and is made available as an electronic reprint with permission of SPIE. One print or electronic copy may be made for personal use only. Systematic or multiple reproduction, distribution to multiple locations via electronic means, duplication of any material in this paper for a fee or for commercial purposes, or modification of the content of this paper are prohibited. 
engines to access humanity's collective knowledge and expertise. The search engines retrieve facts from a growing sea of information. How big is this sea? How can we efficiently navigate to the useful islands of knowledge? How is knowledge interlinked on a global scale? In which areas is it worth investing resources? We don't know. It is not the first time humanity has faced this type of question: it is, however, the first time that there is an opportunity to coordinate efforts across cultures and disciplines to provide answers.

Cartographic maps of physical places have guided humanity’s explorations for centuries. They enabled the discovery of new worlds while marking territories inhabited by unknown monsters. Without maps, we would be lost. Domain maps of abstract semantic spaces (Börner, Chen \& Boyack, 2003; Chen, 2002; Quesada \& de MoyaAnegón, 2007; Shiffrin \& Börner, 2004) aim to serve today’s explorers navigating the world of science. These maps are generated through scientific analysis of large-scale scholarly datasets in an effort to connect and make sense of the bits and pieces of knowledge they contain. They can be used to objectively identify major research areas, experts, institutions, collections, grants, papers, journals, and ideas in a domain of interest. Local maps provide overviews of research topics, their homogeneity, import-export factors, and relative speed of domain growth. They allow one to track the emergence, evolution, and disappearance of topics and help to identify the most promising areas of research.

The remainder of the paper is organized as follows: Section 1 discusses existing work on the design of science maps and the usage of different types of maps in education. Section 2 presents the process of designing hands-on science maps for kids: starting with learning objectives, and proceeding with data acquisition, map design, and exploration guidance. Section 3 reports the results of an informal evaluation of the hands-on science maps for kids. The paper concludes with a discussion of lessons learned and an outlook into future usage of science maps in education.

\section{Review of Existing Work}

This section reviews scientometrics research on the design of science maps as well as existing usage of different map types in educational settings.

\subsection{Towards a Map of Science}

Science maps are also known as scientographs (Garfield, 1986), literature maps, domain maps, or knowledge domain visualizations. First depictions of the structure of science date back to the 13th century. There is the 'tree of science' from the Arbre de Ciència by Raymond Lulle (Lulle, 1295), Christophe de Savigny's classification in his Tableaux Accomplis de Tous les Arts Libéraux of 1587 (Savigny, 1587), through to today's major science classification systems such as the Library of Congress classification schema (Library of Congress, 2008).

In 1939, John D. Bernal a physicist, historian of science, and sociologist of science designed one of the first 'maps of science (Bernal, 1939). The map divides science into a physical, a biological, and a sociological sector and distinguishes fundamental and technical research. Since the 1930s, more than one hundred milestone maps of science have been published in peer-reviewed journals and books. Each added a unique novel view, technique, or visual language to depict the structure and evolution of science. A timeline of the milestone maps can be found in the forthcoming Atlas of Science (Börner, Forthcoming).

Science is performed by people and scholarly and social networks among people have a major impact on the structure and growth of science. Consequently, the study of scholarly networks or 'invisible colleges' (Crane, 1972) is a major research topic in scientometrics. Depictions of social networks, so called sociograms were invented by social scientist Jacob L. Moreno in 1934 (Moreno, 1934). Shortly after, many other social scientists and other scholars start mapping social and other networks.

Early maps were done by hand - no citation index database existed and computers were not yet available. Recent advances in computer technology and software development have made possible the algorithmic creation of data maps from large-scale datasets. Terabytes of scholarly data are processed by means of interconnected computers running advanced software (Atkins et al., 2003).

Recent work by Kevin W. Boyack and Richard Klavans aims to create a global map of and spatial reference system for all sciences (Boyack, Klavans \& Börner, 2005; Klavans \& Boyack, 2006a, 2006b, 2007, Submitted). The maps are generated based upon a large subset of papers purchased from the most comprehensive databases in existence: Science Citation Index (SCI), Social Science Citation Index (SSCI), and Arts and Humanities Index (A\&HI) by Thomson Scientific (Thomson Reuters, 2008a, 2008b, 2008c) and Scopus provided by Elsevier (Elsevier B.V., 2008). 
The ‘2002 Base Map’ (Boyack, Börner \& Klavans, 2007) is exemplarily, shown in Figure 1 (left). It was generated using the following steps:

- $\quad$ The combined SCI/SSCI from 2002, about 1.07M papers, 24.5M references, 7,300 journals were taken as input.

- The similarity between journal pairs is calculated based on bibliographic coupling — the similarity of two papers corresponds to the number references they share.

- The resulting similarity matrix is normalized using cosine $\mathrm{N}_{\mathrm{ij}} / \operatorname{sqrt}\left(\mathrm{N}_{\mathrm{i}} \mathrm{N}_{\mathrm{j}}\right)$.

- DrL's (Martin, 2008; NWB Team, 2006) edge cutting algorithms is applied to reduce the number of edges. Only the strongest links per node are kept. The result is a spatial, force-directed placement layout of all paper nodes in which similar nodes and regions tend to be more similar to each other. VxOrd was an earlier version of this code without the parallel and recursive capabilities.

- Journals were assigned to 671 journal clusters. Journal names can now be used to 'science locate' individuals, institutions, countries, or scientific fields based on their publication record.

- $\quad$ The result is interpreted and labeled manually.

In 2006, this map was the most comprehensive map of science ever generated. The map was used for diverse overlays of funding, see Figure 1 (right). The major difference to other work is that clustering of papers or journals is not based on the original correlation matrix but on the DrL layout, i.e., the position of nodes in a twodimensional space.
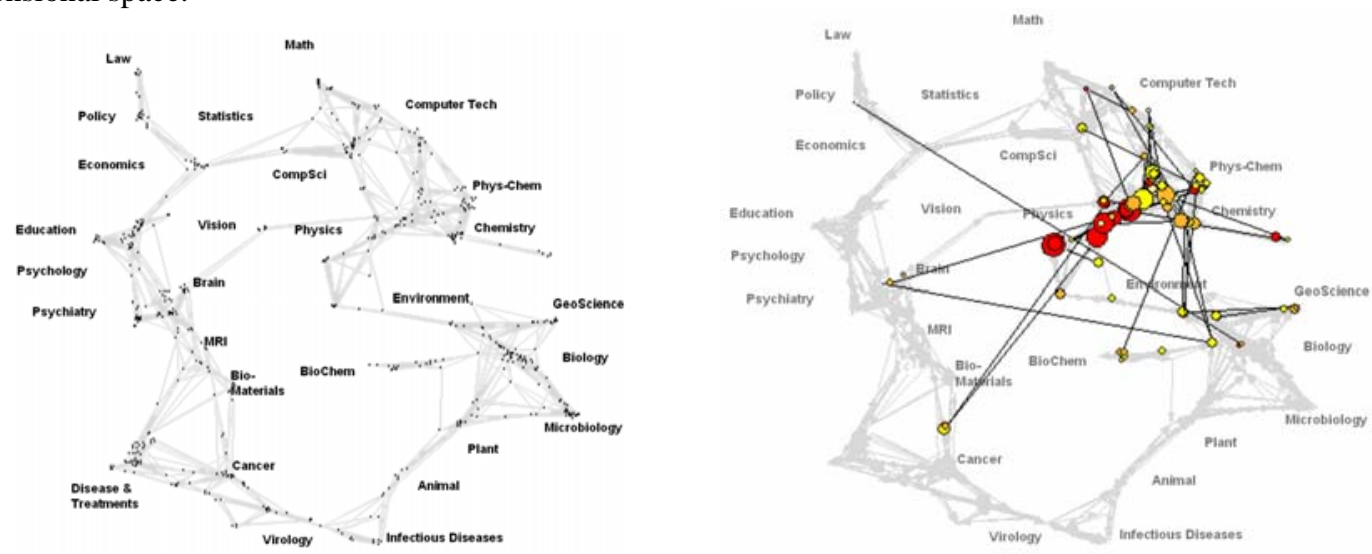

Figure 1: Map of Science (left) with data overlay of funding by the U.S. Department of Energy (right)

However, the communication of the structure and evolution of science at an individual, local, and global scale is non trivial. Top-n lists and timelines are easy to read and understand yet they fail to convey the complex interdependencies of scholarly entities and the feedback loops with which they are involved. The design of reference systems and visual vocabulary to depict science at different scales for different stakeholders is a major research topic (2020 Research Group and Steering Committee, 2006). Today’s maps of science show pure data, see Figure 1. It often takes a database, data analysis and domain expert to interpret and make sense of them. While there are many attempts to make science maps easier to read for science policy makers, business professionals or researchers, we are not aware of any other attempts to design science maps for children.

\subsection{Map Usage in Education}

A useful tool for visualizing large data sets is the network diagram. In the K-12 setting, they are commonly known as concept maps. Concept maps are widely used in education. In first grade, they might communicate the daily schedule. Later, mind maps and argument maps are valuable means to communicate complex systems. Software tools such as Inspiration (Inspiration Software Inc., 2008), Compendium (Compendium Institute, 2008), Let’s Focus (L'Università della Svizzera Italiana, 2008) or Rationale (Austhink Software Pty Ltd., 2008) help visualize (collective) knowledge creation, access, sharing, discussion, and utilization. The maps augment and enhance human intellectual output ultimately leading to improved decision making. As shown in Figure 2, a concept map is made up of four core elements: nodes, links interconnecting the nodes, words describing the meaning of nodes and links, and patterns - such as a hierarchical or circular ordering of the nodes (Conklin, 2005; McKim, 1980; Novak, 1998, 2004; Novak \& Cañas, 2008). 

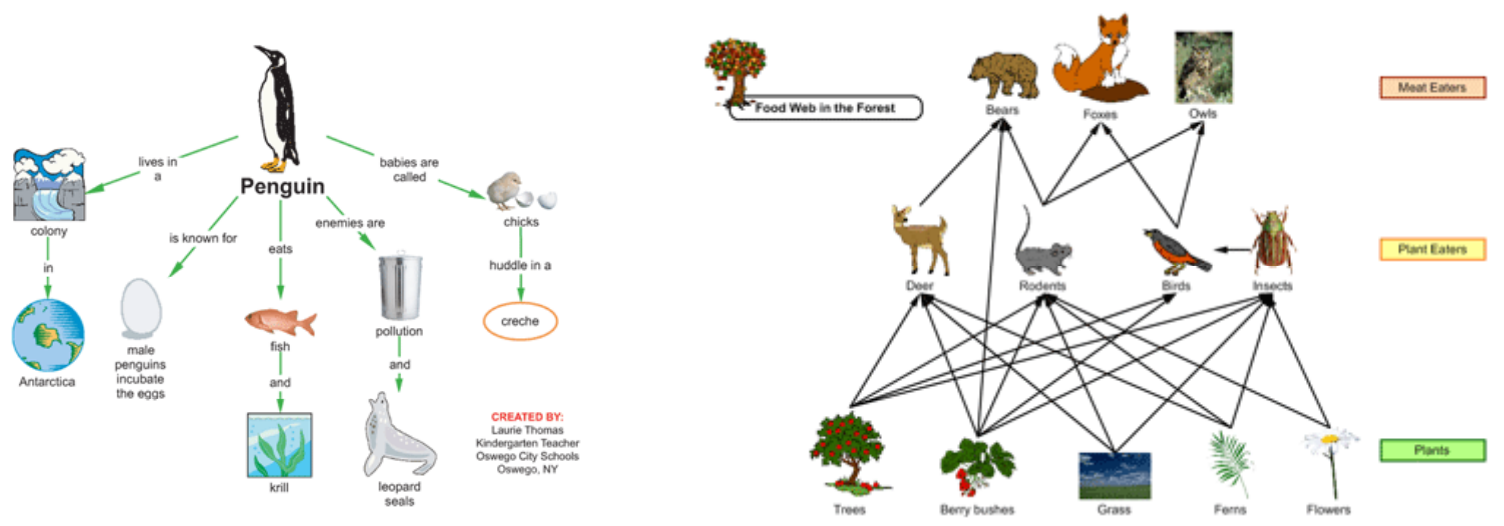

Figure 2: Examples of concept maps used in K-12 education (http://www.inspiration.com/productinfo/kidspiration/using_kids/index.cfm?fuseaction=science)

Science maps can be seen as a special kind of concept maps. They facilitate a spatial understanding of things, concepts, conditions, processes, or events in the human world. While concept maps are rather narrow in scope, science maps can convey the structure of all of science (Hook \& Börner, 2005).

\section{Hands-On Science Maps for Kids}

Ideally, science maps for kids invite children to see, explore, and understand science from above. Science maps are typically dense with information, so a science map for children should make sense of the terms used to represent disciplines and subdisciplines as well as the relationships amongst them. They should illustrate science in ageappropriate ways. They must provide meaningful icons to represent specific disciplines and relationships amongst disciplines in concrete ways coupled to the human experience. One approach is to focus on scientific discoveries and inventions in and amongst disciplines, including the people who made those discoveries or engineered the inventions. Because such inventions and discoveries occur in specific geographical and cultural contexts, this focus also allows the correlation of geospatial data to science maps.

In terms of the user experience, such maps need to be engaging, have a way to allow the user to focus on particular relationships, make correlations between geospatial data and relationships amongst disciplines. Further, it has been established in the literature (Newell, Bülthoff \& Ernst, 2003) that learning happens through a synthesis of modalities, rather than strictly through visual pathways. Thus, combining haptic and visual modalities may increase discrimination and possibly understanding: by navigating the virtual space of science disciplines and geospatial representations through manipulating tactile object and visualization, greater comprehension might result (Bushnell \& Baxt, 1999). Children quite naturally try to make correlations so developing the maps into a matching activity might help students make and question correlations (American Association for the Advancement of Science, 1993; Gopnik \& Astington, 1988).

\subsection{Learning Objectives}

Three major learning objectives were identified in prior works (Palmer, Smith, Hardy \& Börner, 2007; Roberg, 2006):

1. Correlate geospatial and science map space as well as define and understand science disciplines and relationships: The maps for children created for this work are intended to provide a global view of the geographical and scientific origin of major scientists, inventors, and inventions. Hence, two global maps are used and major contributions from all areas of the world and two science maps are used, showing all areas of science. See timeline below for a listing of inventions and inventors used in the two maps.

2. Provide an opportunity to expand the cultural palette of understanding, discovery and invention to a global scale: While the base map of our world is taught extensively in school, the base map of science is less well known. People in the U.S. may have an easy time placing U.S. and European scientists, inventors, and inventions; yet the placement of puzzle pieces in non-European-American regions could prove rather challenging.

3. Provide an experience that is engaging and addresses at least two learning modalities: The puzzle maps are hands-on, providing a tactile exercise that allows the use of spatial motor skills to explore the shape of science and to remember where puzzle pieces go. Ideally, children and adults walk away with a more global understanding of 
our world and the world of science. They now see and sense that inventors/scientists and inventions/discoveries happen all over the world and over all areas of science. Ideally, they locate themselves within the cultural context of science and engineering.

\subsection{Data Acquisition}

The science reference world map and science map were taken from the Illuminated Diagram display by Kevin Boyack, Richard Klavans, and W. Bradford Paley (Boyack, Klavans, Paley \& Börner, 2007). The science map has the very same layout as the '2002 Base Map' (Boyack, Börner et al., 2007) discussed in section 1.1 yet edges do avoid nodes leading to a more legible, organic looking layout.

Inventions and inventors were selected based on the study of diverse science encyclopedias, Web resources, and expert suggestions. It is interesting to note that books on science and inventions in America feature mostly American scientists, inventors and inventions. The same type book in Europe features mostly European ones and this might hold true for other continents as well. However, inventors and inventions exist everywhere. All areas of science contribute major inventors and inventions.

\subsection{Map Design}

Both maps have a 'pure data' layer that lets viewers imagine the amounts of records shown as well as a watercolor painting layer that renders geographic places and scientific spaces more tangible through icons representing science disciplines and discoveries/inventions. One map shows our world and the places where science is practiced or researched. The other shows major areas of science and their complex interrelationships, see Figure 3 and 6 (right).
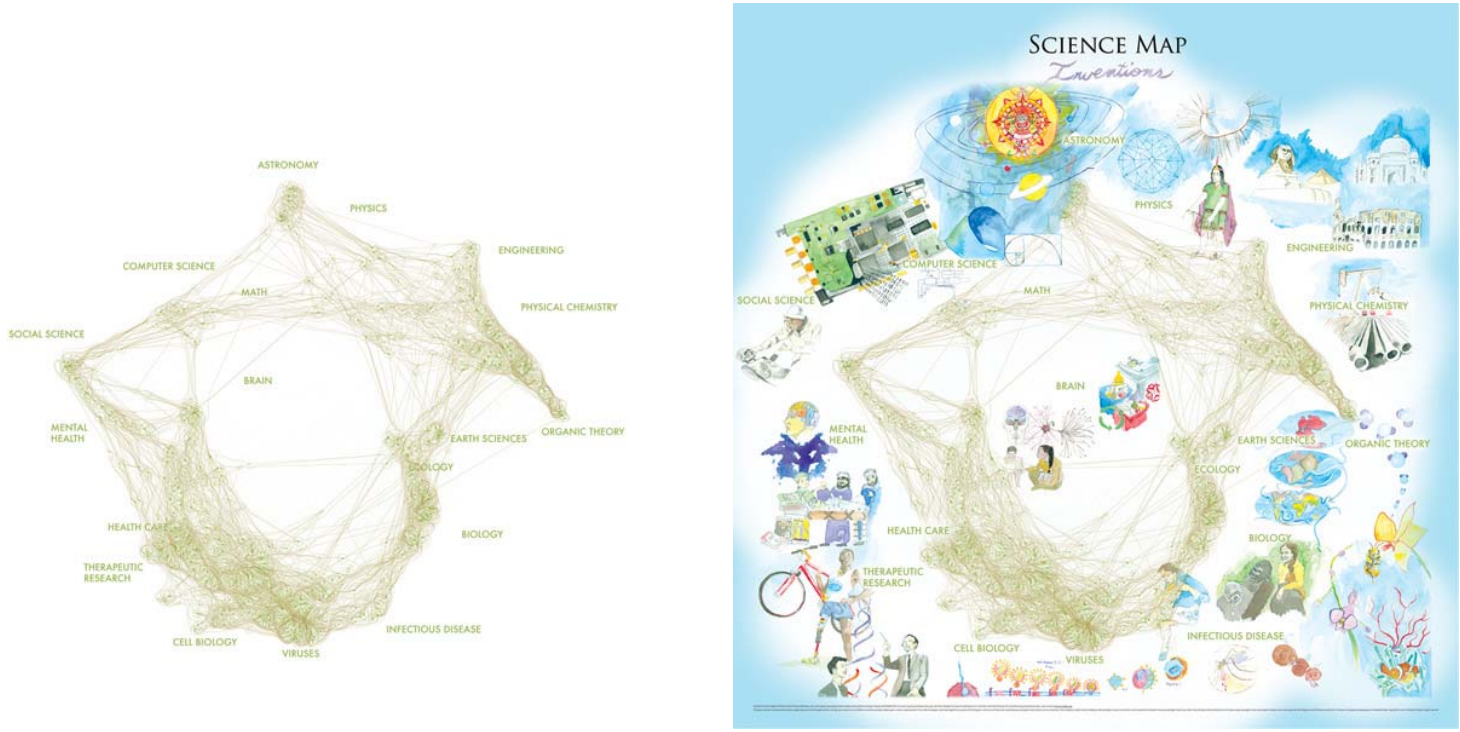

Figure 3: Pure data maps (left) and map for children enhanced with watercolor paintings

Watercolor paintings were rendered digitally and overlaid onto computer graphic images to make different continents as well as different areas of science more understandable. Children and adults alike are invited to help solve the puzzle by placing major scientists, inventors, and inventions at their proper places. Eighteen puzzle pieces that show major inventions on the front and major inventors on the back need to be positioned in the right place on Earth. A timeline of the pieces is shown in Figure 4. Description of all inventions and inventors are available online at http://scimaps.org/kids/ (Börner, Smith, Hardy \& Palmer, 2006). 


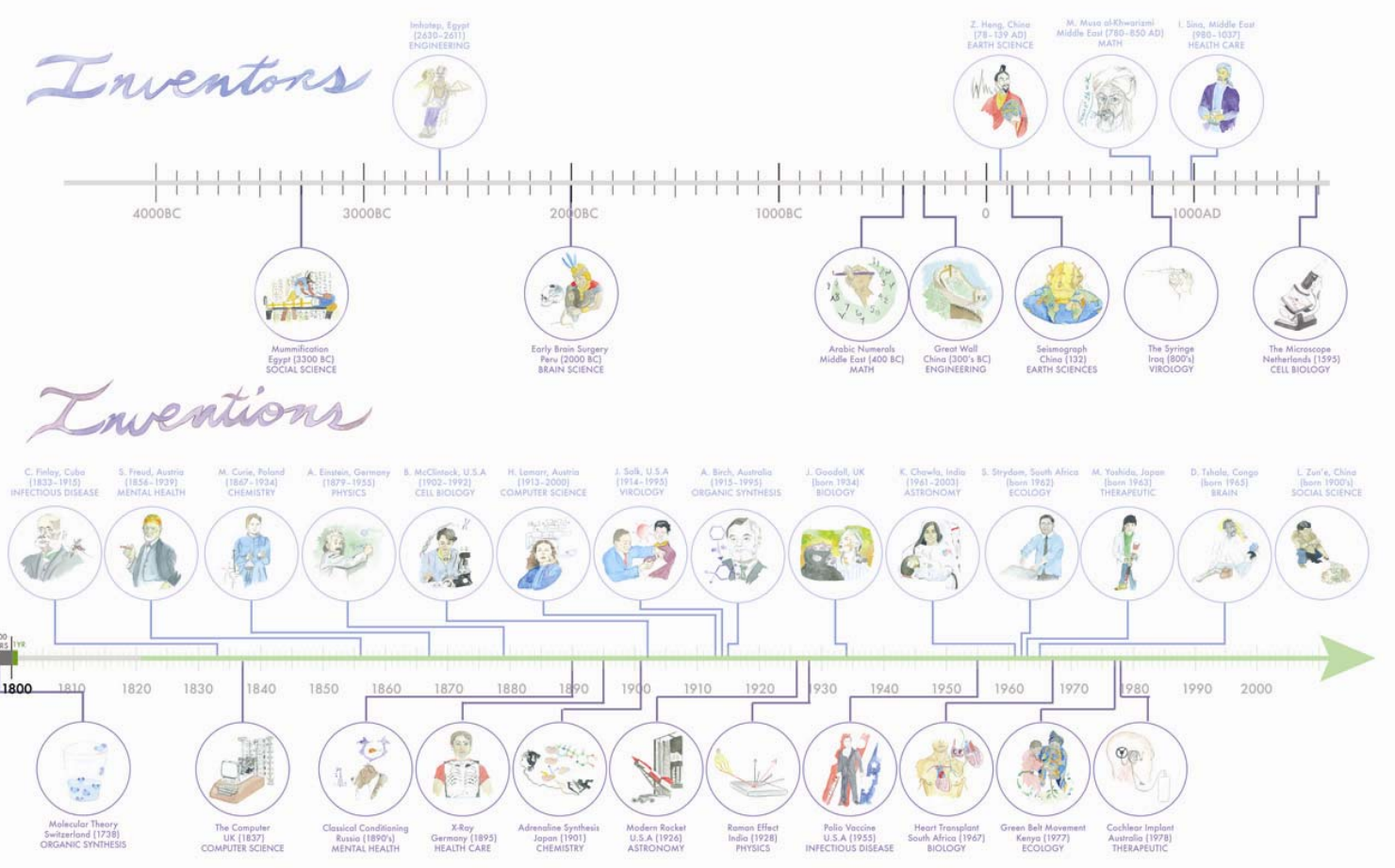

Figure 4: Puzzle stones of inventions and inventors organized by time

Different designs of the layering and the puzzle stones were explored. A photo of hand drawn tracks on the science map - they need to work on both sides! - and the final puzzle map design are shown in Figure 5. Images were printed on vinyl adhesive sheets mounted to $5 \mathrm{~mm}$ Plexiglas. Slots were routed and marker "stones" (researchers/inventors and discoveries/inventions) screw mounted through slots to allow them to be moved over the map surfaces. Maps had side panels mounted to them to allow them to be used vertically.
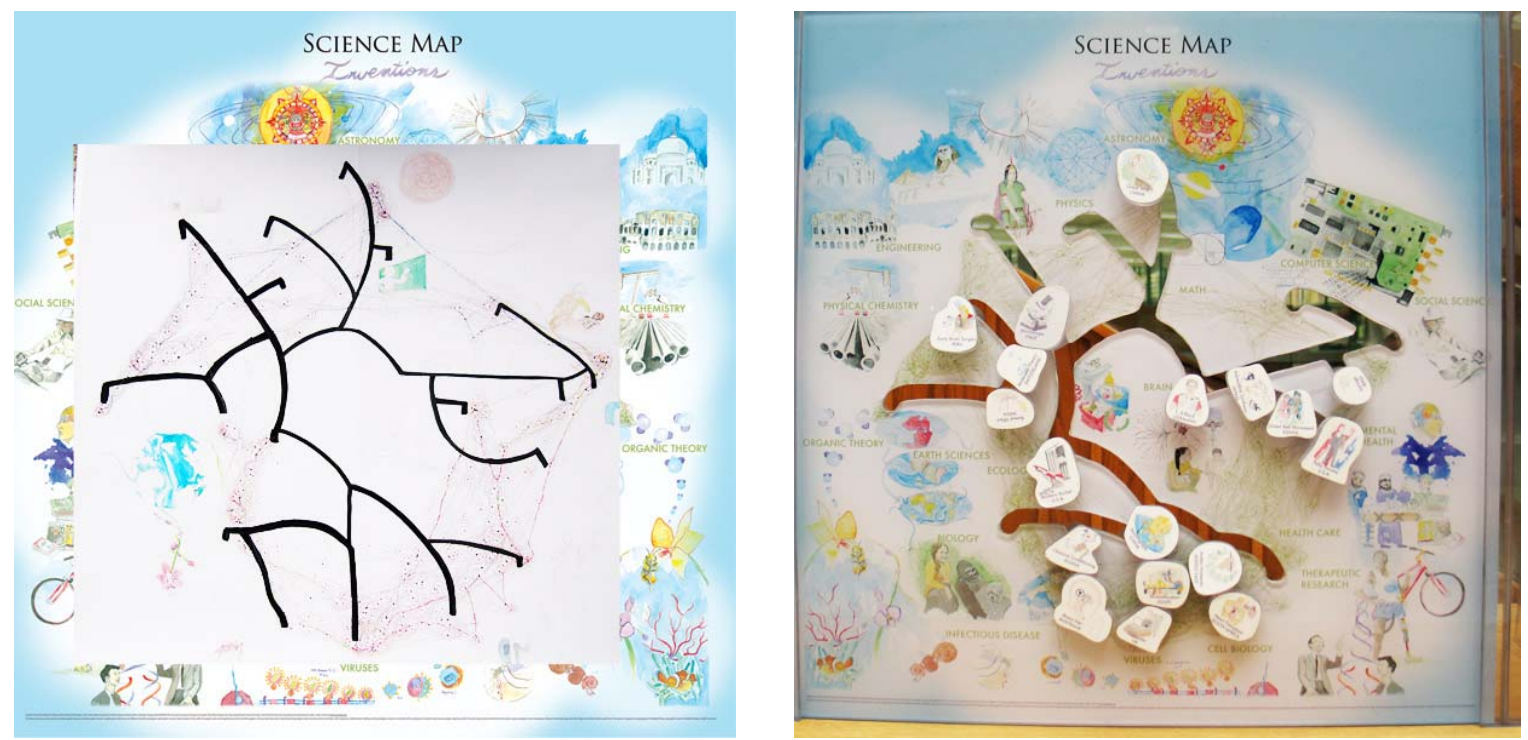

Figure 5: Creating tracks for puzzle stones - photos of hand drawn tracks on printout (left) and final design (right)

\subsection{Guiding Exploration}

The typical process for a user is to explore each of the two geospatial or science space maps. They start by selecting either of the two map sets. They then decide if they want to place famous people or major inventions first. 
They can then turn the map over when they are done and start again. Many hints are embedded in the drawings to aid in finding the perfect place for each puzzle piece. In addition, a key is provided to fill in knowledge gaps, since the researchers assumed that there would not be complete prior knowledge of all the scientists/inventors or discoveries/inventions.

Children might like to plot the "life lines" of major scientists — for example Albert Einstein. While one can plot his relationship to the places he worked at geospatially and through time by moving the "Einstein Stone" amongst these locations, where would he go on a map of science? Given that he made major contributions to several major areas, should we cut him into pieces? How many? Should we place him in the area of his major contribution? Which area is this? Or in the middle of his contributions which might potentially be 'nowhere land'? Perhaps he should move back and forth between areas of study he explored. Or maybe there should be multiple Einsteins for different disciplines? Where do all other inventions and inventors go and what is their relative position to each other? It might be more important that children ask these questions rather than the answers they come up with. The maps are intended to deepen inquiry and stimulate questions about the complexity of science rather than to provide simplistic go, no go answers to questions about the structure of science.

\section{Formal and Informal Evaluation}

\subsection{Interactive Exploration in Classroom Settings}

A community visitor opportunity was used to introduce maps to science to children in a combined $1^{\text {st }}$ and $2^{\text {nd }}$ grade classroom in Bloomington, Indiana in 2005, see Figure 6 (left).

During the first visit, children explored different maps of the world with overlays of animal types, minerals, political boundaries. They showed the birthplace of famous inventors and inventions and pointed out Columbus' travels on the map. In addition, we let half of the class explore our Earth interactively using Google Earth and children zoomed into their home, or traveled virtually to their grandma in Poland and their daddy on a business trip in the U.K. The other half received help in marking their family's home on a street map of Bloomington. After 20 minutes the groups switched. It was surprising to see with what ease these 6-8 year old children managed to navigate, manipulate and make sense of different type of paper maps and digital maps.

During the second visit, we showed children maps of science that were enhanced with bright colors denoting the different areas of science, larger labels and icons for different inventions/tools. We asked them to identify major areas of science and to show the 'birth place' of famous inventors and inventions. We discussed that many scientists and inventors traverse science widely - analogous to Columbus' travels yet in science-land. We asked children to glue little stars on the area they want to be in and a seven year old girl came forward to tell that she would like to become a nuclear physicist and placed her start in the correct area. We also gave children a coloring exercise that lets them zoom into Earth Science, then further into Entomology, and let them color in an insect (see Roberg, 2005). The children seemed to effortlessly transfer their knowledge of geospatial maps to science maps.

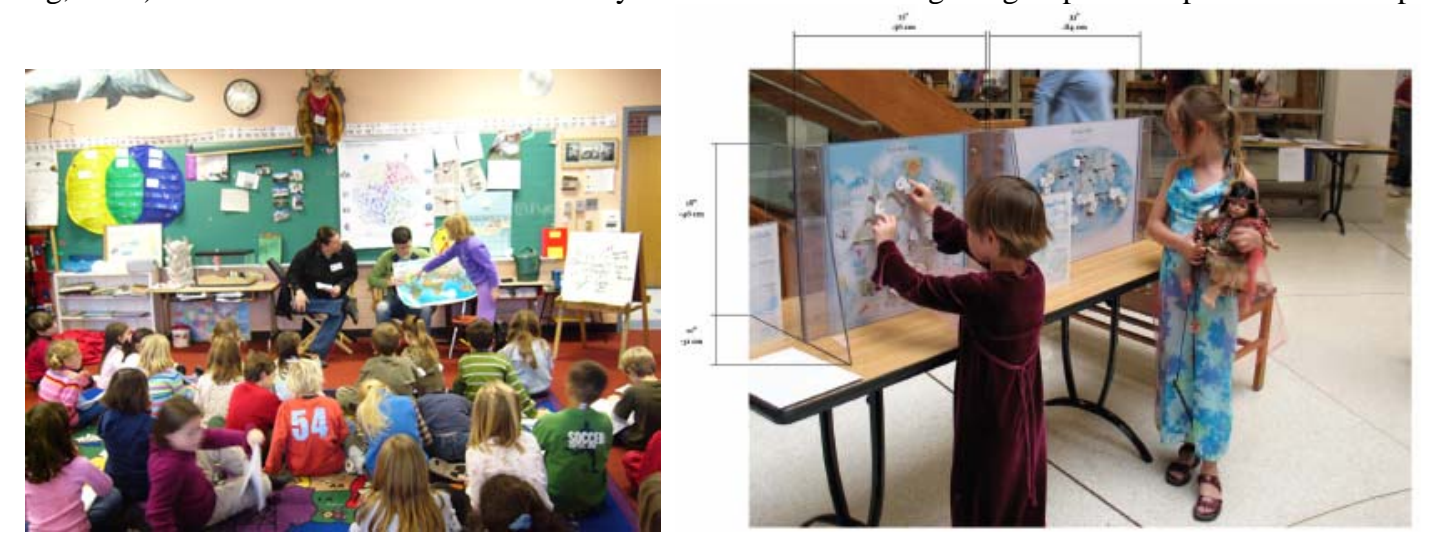

Figure 6: Formal classroom learning environment (left) and informal library environment (right).

\subsection{Display at Science Museums}

The hands on puzzle maps are an integral element of the Places and Spaces: Mapping Science exhibit, online at http://scimaps.org. They have been on display at the New York Hall of Science (where they were created), the 
American Museum for Science (AMSE) and Energy in Oak Ridge, TN, and in diverse libraries in the U.S. and Canada among others.

Figure 6 shows a normal setup that comprises the two maps, a key with information on all scientists/inventors and for all discoveries/inventions, together with a label with more information about the maps. Children can explore these maps from any side, start with the world map or the science maps and turn the maps (or walk around them) to slide scientists/inventors or discoveries/inventions to their correct places.

In informal learning environments the kid's puzzle maps are integral parts of the Places and Spaces exhibition, so were in a context of a variety of geospatial and science maps. Anecdotally, the kids maps got extensive use, there is a tendency for users to try to use both sides at once, or multiple visitors using a single map, also because there was no Internet access at the exhibition location, printed reference keys were used to describe inventors and inventions. Visitors made extensive use of these keys, particularly when parents or teachers were mediating the experience with the children. Some kind of facilitation improves effectiveness of the experience. Also, because this experience functions best with individuals rather than groups, a quieter environment lab or classroom environment is likely a preferred location to an open gallery.

\subsection{Kids Contest}

Also as part of the Places \& Spaces: Mapping Science exhibit, we invited kids of ages 4-14 to draw their favorite scientist or their favorite science experiment and to submit it together with a 25-100 words story to the exhibit curators, see flyer at http://scimaps.org/mcpl/Kids_Contest.pdf. Independent judges then rated the entries by age group and winners were announced at an official awards ceremony and received a science encyclopedia, a science experiments kit and a membership to the local science museum. It is interesting to note that the \$300 spent for the prizes enticed a major part of a town's population (all kids aged 4-14 their siblings, parents, and co-located grandparents) to think, write, and paint about science.

During the showing at the Monroe Country Public Library in Bloomington, Indiana and the AMSE exhibit more than 140 drawings and associated stories were submitted. Two drawings: A portrait of Albert Einstein by Luke Layton (age 11) and "Nature - Science is All Around Us” by JoHanna Sanders (age 12) are shown in Figure 7.
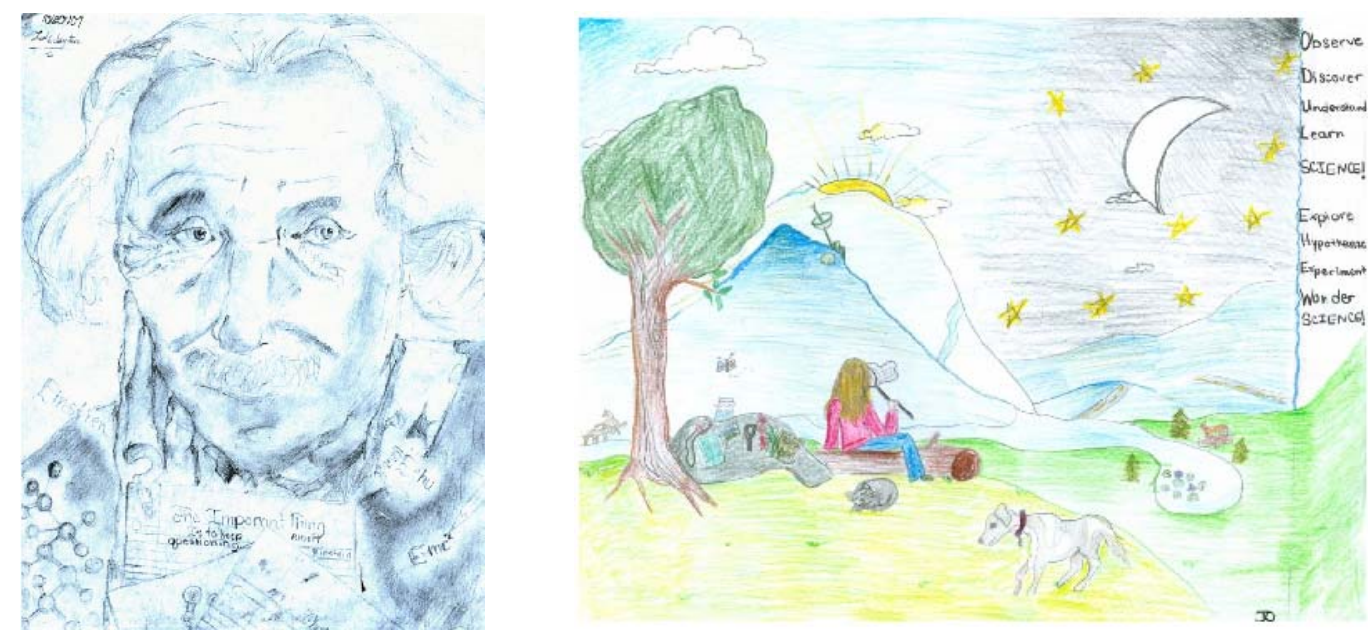

Figure 7: Albert Einstein by Luke Layton and “Nature - Science is All Around Us” by JoHanna Sanders

Curious to know what scientists/inventors and discoveries/inventions children of what age submit, we created a network visualization of different node types, see Figure 8. In it, red nodes represent all children in one age group. The number next to each red node indicates how many submissions came from this age group. The red nodes are connected to 'Experiment' nodes in green and 'Scientist' nodes in purple that were submitted by them. The 'Experiment' and 'Scientist' nodes are size coded by the number of times they were submitted. 


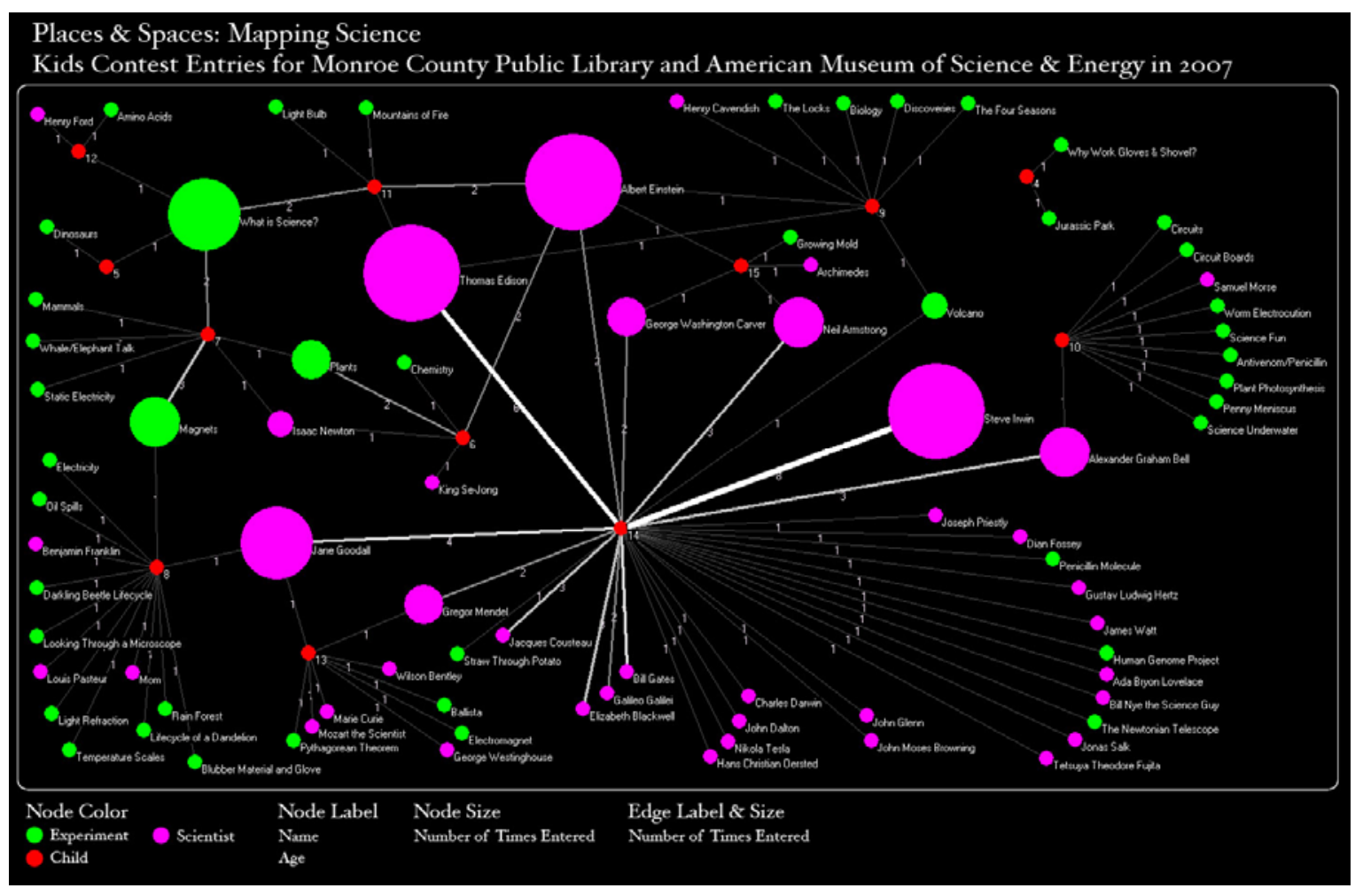

Figure 8: Network of children of different ages and their submissions

As can be seen, most submissions came from a class of 14 year olds. The top three scientists are Albert Einstein, Thomas Edison, and Steve Irwin, closely followed by Jane Goodall. The top three experiments are "What is Science?”, "Magnets”, and "Plants”. Paintings and stories of "Bill Gates” and “Jurassic Park” were also among the entries.

\section{Discussion and Outlook}

The researchers believe that science maps for kids are a means to expose young people to the structure of science and the methods, interfaces and types of visualizations used to represent large-scale data sets. But there are many challenges to children understanding something as complex as science. Perhaps the most significant problem that arose in developing this activity is the sheer density of data, new ideas, and terminology that must be assimilated to obtain the desired global understanding. This is a significant issue around the teaching of science in general, but is further complicated in addressing higher-order concepts like the structure of science. Ideally, such discussions would enable and engender changes in the emphasis of school curricula to coincide with making correlations amongst science disciplines instead of maintaining their compartmentalization. Benchmarks for science teaching and learning have called for this to happen (American Association for the Advancement of Science, 1993) and the research community already works this way, yet there is a great deal of resistance in the academic community. The science maps for kids cannot address this issue directly, but are tools to aid in making a case for pedagogical change.

Another challenge is the fact that currently science maps address a small audience, and observations of behaviors and understanding of outcomes is strictly anecdotal. A more structured study with a larger cohort is needed, along with some kind of control group to quantify and qualify the nature of learning that occurs by use of such maps of science. This should include some prototyping, as well as pre and post testing. Indeed there is strong interest in such research because there are implications for visualization of many kinds of large, complex data sets. Such a study could provide useful data for the visualization community in general and identify learning outcomes from such data sets. Perhaps even develop models for data visualization, impact teaching and learning, game design, and HCI usability heuristics. Such research will also help to make science maps a much more useful tool for teaching science, as well as analyzing the structure of science for policy and decision making.

Science maps could one day become standardized visual interfaces to educational resources. The holdings of science experiments in national and international science museums, online and offline resources such as books, 
teaching material, exercises, even learning partners can all be mapped and explored. Many educational resources exist, e.g., in the OER Commons a teaching and learning network of shared materials or the National Science Digital Library (The Institute for the Study of Knowledge Management in Education (ISKME), 2007; The National Science Foundation, 2008). Visual interfaces to these resources help understand their coverage and support navigation and utilization (Börner \& Chen, 2002).

Science maps support retrieval by association: a more intuitive approach to exploring information topics. Most scholarly works as well as textbooks are organized in a linear fashion: one topic follows after another. However, our brains work by association - we learn by connecting new concepts to existing ones. The network of learned concepts can then be traversed and understood in a non-linear manner. Wales' Wikipedia (The Wikimedia Foundation, 2008) and Burke's Knowledge Web (The James Burke Institute, 2008) are excellent examples for knowledge structures that support non-linear traversal and discovery. Visualizations of network structures support the visual identification of major interconnections or 'backbones' and the discovery of highly interconnected knowledge items or clusters. They provide a bird's eye view of the density and layout of the knowledge network in support of navigation and sense making.

Last but not least, science maps can be used as a classroom teaching tool. Given a specific topic, say sustainability, a teacher has to identify what areas, experts, readings, etc. should be covered and what sequence of units or pathway might be best to communicate the structure and evolution of this topic over time. A teacher might decide to use the topic coverage and sequence given in a textbook. If no textbook exists, s/he is often left to her/his judgment. As teaching topics become ever more interdisciplinary and evolve at rapid pace this becomes a daunting if not impossible task. Science maps can help delineate a domain. For example, a query for 'sustainability' would highlight relevant research and/or existing educational material. Review articles or major books, resources that fit the age group, context and technical resources can be easily identified. Plus, the structure and evolution of a research topic can be animated and demonstrated to the class (Ke, Börner \& Viswanath, 2004; Roberg, 2006).

\section{Acknowledgements}

We would like to thank Ben Shneiderman for inspiring the design of science maps for kids. Ian Aliman and Nicole (Nikki) Roberg collaborated with us on initial work on this topic. Michael Lane, Director of Exhibit Services at the New York Hall of Science provided expert advice and manufactured the physical maps. Mark A. Price formatted the references and proofread a final draft of this paper. This work is supported in part by the Cyberinfrastructure for Network Science Center at Indiana University, the New York Hall of Science, and the National Science Foundation under award IIS-0238261, IIS-0715303, and SBE-0738111. Any opinions, findings, and conclusions or recommendations expressed in this material are those of the author(s) and do not necessarily reflect the views of the National Science Foundation.

\section{References}

2020 Research Group and Steering Committee. (2006). Towards 2020 Science. Microsoft Corporation. Available at http://research.microsoft.com/towards2020science/background_overview.htm, accessed on 7/31/2008.

American Association for the Advancement of Science. (1993). Project 2061: Benchmarks for Science Literacy. Available at http://www.project2061.org/, accessed on 07/31/2008.

Atkins, Daniel E., Kelvin K. Drogemeier, Stuart I. Feldman, Hector Garcia-Molina, Michael L. Klein, David G. Messerschmitt, Paul Messian, Jeremiah P. Ostriker \& Margaret H. Wright. (2003). Revolutionizing Science and Engineering through Cyberinfrastructure. Arlington, VA: National Science Foundation.

Austhink Software Pty Ltd. (2008). Rationale: Simply Better Thinking. Available at http://rationale.austhink.com/, accessed on $7 / 30 / 2008$.

Bernal, John. D. (1939). The Social Function of Science. London: Routledge \& Kegan Ltd.

Börner, Katy. (Forthcoming). Atlas of Science. Redlands, CA: ESRI.

Börner, Katy \& Chaomei Chen. (2002). "Visual Interfaces to Digital Libraries: Motivation, Utilization and SocioTechnical Challenges." In Katy Börner \& Chaomei Chen (Eds.), Lecture Notes in Computer Science: Visual Interfaces to Digital Libraries, 2539. Berlin/Heidelberg: Springer. 1-9

Börner, Katy, Chaomei Chen \& Kevin W. Boyack. (2003). "Visualizing Knowledge Domains." In Blaise Cronin (Ed.), Annual Review of Information Science and Technology, 37, Medford, NJ: American Society for Information Science and Technology. 179-255.

Börner, Katy, Julie Smith, Elisha F. Hardy \& Fileve Palmer. (2006). Hands-On Science Maps for Kids. Indiana University. Available at http://scimaps.org/kids/, accessed on 7/30/08.

Boyack, Kevin W., Katy Börner \& Richard Klavans. (2007). Mapping the Structure and Evolution of Chemistry Research. Paper presented at the 11th International Conference of the International Society for 
Scientometrics and Informetrics, Daniel Torres-Salinas \& Henk F. Moed (Eds.), Madrid, Spain: Consejo Superior de Investigaciones Cientificas. 112-123.

Boyack, Kevin W., Richard Klavans \& Katy Börner. (2005). Mapping the Backbone of Science. Scientometrics 64(3). Berlin/Heidelberg: Springer. 351-374.

Boyack, Kevin W., Richard Klavans, W. Bradford Paley \& Katy Börner. (2007). Mapping, Illuminating, and Interacting with Science, The 34th International Conference and Exhibition on Computer Graphics and Interactive Techniques. San Diego, CA: SIGGRAPH 2007.

Bushnell, Emily W. \& Chiara Baxt. (1999). Children's Haptic and Cross Modal Recognition With Familiar and Unfamiliar Objects. Journal of Experimental Psychology: Human Perception and Performance, 25(6) Washington, D.C.: American Psychological Association. 1867-1881.

Chen, Chaomei. (2002). Mapping Scientific Frontiers. London: Springer Verlag.

Compendium Institute. (2008). Compendium Institute. Available at http://compendium.open.ac.uk/institute/, accessed on 7/30/2008.

Conklin, Jeffrey. (2005). Dialogue Mapping: Building Shared Understanding of Wicked Problems. Hoboken, NJ: Wiley.

Crane, Diana. (1972). Invisible Colleges: Diffusion of Knowledge in Scientific Communities. Chicago: University of Chicago Press.

Elsevier B.V. (2008). Scopus. Available at http://www.scopus.com/scopus/home.url, accessed on 7/28/2008.

Garfield, Eugene. (1986). Essays of an Information Scientist: Towards Scientography (Vol. 9). Philadelphia, PA: ISI Press.

Gopnik, Alison \& Janet W. Astington. (1988). Children's Understanding of Representational Change and Its Relation to the Understanding of False Belief and the Appearance-Reality Distinction. Child Development, 59(1) Ann Arbor, MI: Society for Research in Child Development. 26-37.

Hook, Peter A. \& Katy Börner. (2005). "Educational Knowledge Domain Visualizations: Tools to Navigate, Understand and Internalize the Structure of Scholarly Knowledge and Expertise." In Amanda Spink \& Charles Cole (Ed.)^(Eds.), New Directions in Cognitive Information Retrieval. Amsterdam: Springer Verlag.

Inspiration Software Inc. (2008). Inspiration Software, Inc. Available at http://www.inspiration.com/, accessed on 7/30/2008.

Ke, Weimao, Katy Börner \& Lalitha Viswanath. (2004). Major Information Visualization Authors. Available at http://iv.slis.indiana.edu/ref/iv04contest/Ke-Borner-Viswanath.gif, accessed on 7/30/08.

Klavans, Richard \& Kevin W. Boyack. (2006a). Identifying a Better Measure of Relatedness for Mapping Science. Journal of the American Society for Information Science and Technology 57(2). Silver Springs, MD: American Society for Information Science and Technology. 251-263.

Klavans, Richard \& Kevin W. Boyack. (2006b). Quantitative Evaluation of Large Maps of Science. Scientometrics 68(3). 475-499.

Klavans, Richard \& Kevin W. Boyack. (2007). Is There a Convergent Structure to Science? Paper presented at the The 11th International Conference of the International Society for Scientometrics and Informetrics, Madrid: Consejo Superior de Investigaciones Cientificas. 437-448.

Klavans, Richard \& Kevin W. Boyack. (Submitted). Toward a Consensus Map of Science. (where was this submitted?

L'Università della Svizzera Italiana. (2008). Let's Focus: Drawing Attention. Available at http://en.letsfocus.com/index.php?option=com_frontpage\&Itemid=1, accessed on 7/30/2008.

Library of Congress. (2008). Library of Congress. Available at http://www.loc.gov/index.html, accessed on 7/30/2008.

Llull, Ramon. (1295). Arbre de Ciència. Roma.

Martin, Shawn. (2008). Software by Shawn Martin: DrL; Distributed Recursive (Graph) Layout. Available at http://www.Cs.sandia.gov/ smartin/software.html, accessed on 7/30/2008.

McKim, Robert H. (1980). Thinking Visually: A Strategy Manual for Problem Solving. Belmont, CA: Lifetime Learning Publications.

Moreno, Jacob L. (1934). Who Shall Survive? New York, NY: Beacon House.

Newell, Fiona N., Heinrich H. Bülthoff \& Marc O. Ernst. (2003). Cross-Modal Perception of Actively Explored Objects. Available at http://www.eurohaptics.vision.ee.ethz.ch/2003/43.pdf, accessed on 07/31/2008.

Novak, Joseph D. (1998). Learning, Creating and Using Knowledge: Concept Maps as Facilitative Tools in Schools and Corporations. Mahwah, NJ: Lawrence Erlbaum Associates.

Novak, Joseph D. (2004). A Science Education Research Program that Led to the Development of the Concept Mapping Tool and a New Model for Education. Available at http://cmc.ihmc.us/papers/cmc2004-286.pdf, accessed on 7/30/2008.

Novak, Joseph D. \& Alberto J. Cañas. (2008). The Theory Underlying Concept Maps and How to Construct and Use Them. Available at 
http://cmap.ihmc.us/Publications/ResearchPapers/TheoryCmaps/TheoryUnderlyingConceptMaps.htm, accessed on $7 / 30 / 2008$.

NWB Team. (2006). Network Workbench Tool. Indiana University and Northeastern University. Available at http://nwb.slis.indiana.edu, accessed on 04/22/08.

Palmer, Fileve, Julie Smith, Elisha F. Hardy \& Katy Börner. (2007). Hands On Science Maps for Kids. Indiana University. Available at http://www.scimaps.org/exhibit/kids/, accessed on 7/30/2008.

Quesada, Benjamin Vargas \& Félix de Moya-Anegón. (2007). Visualizing the Structure of Science. London: Springer, Ltd.

Roberg, Nicole. (2005). My Science Story. Indiana University. Available at http://scimaps.org/kids/Coloring.pdf, accessed on 7/30/2008.

Roberg, Nicole A. (2006). Science Maps for Kids, Presentation at the 10th International Information Visualization Conference. London, UK.

Savigny, Christophe de. (1587). Tableaux Accomplis de tous les arts libéraux. Paris.

Shiffrin, Richard M. \& Katy Börner, Eds. (2004 ). Mapping Knowledge Domains. PNAS, Vol. 101 Suppl. 1.

The Institute for the Study of Knowledge Management in Education (ISKME). (2007). OER Commons: Open Educational Resources. Available at http://www.oercommons.org/, accessed on 7/30/2008.

The James Burke Institute. (2008). Knowledge Web: A Project of the James Burke Institute. Available at http://www.k-web.org/, accessed on 7/30/2008.

The National Science Foundation. (2008). The National Science Digital Library. Available at http://nsdl.org/, accessed on 7/31/2008.

The Wikimedia Foundation. (2008). Wikipedia. Available at http://wikipedia.org/, accessed on 7/30/2008.

Thomson Reuters. (2008a). Arts and Humanities Citation Index ${ }^{\circledR}$ Available at http://scientific.thomsonreuters.com/products/ahci/, accessed on 7/30/2008.

Thomson Reuters. (2008b). Science Citation Index® Available at http://scientific.thomsonreuters.com/products/sci/, accessed on 7/30/2008.

Thomson Reuters. (2008c). Social Sciences Citation Index ${ }^{\circledR}$. Available at http://scientific.thomsonreuters.com/products/ssci/, accessed on 7/30/2008. 